DOI: 10.19195/0137-1150.163.11

\author{
MARIA MIKHAILOVA \\ МГУ им. М.В. Ломоносова, Rosja \\ mary1701@mail.ru
}

\title{
Творческие взаимоотношения Ивана Бунина и Галины Кузнецовой как конфликт молодости и старости
}

Круг бунинских учеников не был широк - в годы эмиграции рядом с ним почти постоянно были только Лев Зуров, Николай Рощин, Галина Кузнецова. И все они в целом не оправдали его надежд. Зуров во многом держался особняком, не во всем принимая советы мэтра. Кроме того, душевное заболевание и увлеченность археологией не позволили ему войти в тесный контакт с бунинской творческой индивидуальностью. Рощин просто не был особенно даровит. Другое дело Галина Кузнецова, несомненно, обладавшая незаурядным талантом. В ней для Ивана Бунина счастливо соединилась возлюбленная и ученица. Или, по крайней мере, он долгое время предполагал существование такого соединения и надеялся, что оно будет долгим и гармоничным. А в глубине души он связывал с ним еще и возвращение молодости, рождение новых замыслов и планов. Спустя шестнадцать лет он подвел итог этому периоду, констатируя теперь не только собственную опустошенность, не только отсутствие любовных чувств, но и невозможность сохранения между собой и бывшей возлюбленной даже простых человеческих связей („совсем, совсем чужие”1), сделав грустную запись в дневнике: „Как молод я был тогда”2 .

Однако и творческие контакты, которые предполагались при знакомстве (со стороны Кузнецовой уж точно), по сути, не были поддержаны контактами человеческими, что до поры до времени каждый из участников этого союза

${ }^{1}$ И.А. Бунин, „...Когда переписываются близкие люди”. Письма И.А. Бунина, В.Н. Буниной, Л.Ф. Зурова к Г.Н. Кузнеиовой и М.А. Степун. 1934-1961, „Новые материалы”, вып. III, сост., подгот. текста, науч. аппарат Е.Р. Пономарева и Р. Дэвиса, Москва 2014, с. 596.

2 Ibidem. 
пытался скрыть от самого себя. Дольше всех находился в заблуждении Бунин, ибо предпочитал видеть развитие отношений в том идеальном ракурсе, который рисовал в своем воображении, тем более что история литературы знала немало прецедентов подобных связей. Он вообразил, что в лице Кузнецовой имеет не только молодую возлюбленную, но и того начинающего автора, который всеми силами стремится войти в писательский круг, который не помышляет ни о чем другом, как о постоянном творческом совершенствовании, и ради этого готов отказаться от радостей жизни, жертвуя всем ради искусства. Однако реальность развивалась по законам, почти ни в чем не совпадавшим с бунинскими представлениями. И это неожиданно обнажает противоречие между проницательностью Бунина как художника-психолога и его житейской или даже в большей степени мужской наивностью, которая пасует перед женской если не хитростью, то, во всяком случае, умением приспособиться к предлагаемым обстоятельствам.

События, развивавшиеся на юге Франции, в Грассе, на протяжении нескольких лет, неумолимо свидетельствуют, что Бунин был во многом слеп относительно характера Кузнецовой, её житейских воззрений, тайных желаний - словом, всего того, что довольно рано сформировало её натуру. Диагноз этого состояния она вложила в уста критика Мусатова (за которым угадывается Владислав Ходасевич) из собственного рассказа Художник: „У вашего поколения несчастливая звезда. Вы, не успевши ничего увидеть, были выброшены из России и предоставлены самим себе"3. Вот она и спешила увидеть, впитать, вкусить, насытиться, чего Бунин не принимал во внимание и не понимал.

Конечно, следует учитывать, что и Кузнецова очень удачно подыгрывала бунинскому „моделированию” действительности. Она женским чутьем довольно рано угадала, какою хочет видеть её Учитель, и довольно успешно пыталась соответствовать нарисованному в его сознании облику. Для неё пребывание в семье Буниных было (особенно на первых порах) „травматическим" (она выступала в качестве ученицы мэтра, его секретаря, подруги жены писателя и даже в чем-то ее наперсницы, нередко ей приходилось быть в какой-то степени и хозяйкой дома, принимающей множество гостей и коллег хозяина „Бельведера”, поскольку Вера Николаевна Бунина не очень охотно хозяйничала), поэтому способом „выживания” она избрала демонстрацию слабости, бесприютности, гонимости, беззащитной женственности. Это очевидно должно было вызывать сочувствие и сострадание окружающих (и в первую очередь Бунина). Недаром Вера Николаевна в своих записях неоднократно повторяет, что муж не любит Галину, а жалеет ее ${ }^{4}$ !

${ }^{3}$ Г. Кузнецова, Художник, [в:] Мы. Женская проза русской эмиграции, сост., вступ. статья и комментарии О.Р. Демидовой, Санкт-Петербург 2003, с. 298.

${ }^{4}$ Показательна следующая запись: „[...] у него к Г(алине) вовсе не любовь, не страсть, а какая-то жалость, которую она умеет внушать к себе мужчинам вместе с идеализацией своей личности” (И.А. Бунин, „,...Когда переписываются близкие люди”, с. 570). 
Кузнецова именно эти качества пыталась воспроизвести в своих героинях. На страницах её произведений появляется трогательная, сломленная обстоятельствами, поддающаяся влиянию извне молодая женщина, вынужденная действовать вопреки своим нравственным убеждениям. В этом образе, безусловно, репродуцирован облик автора. Вернее, такой хочет видеть себя сама Кузнецова и такой хочет предстать перед окружающими. Доминантой характера героини ее прозы становится слабоволие, неспособность к борьбе и сопротивлению. К слову, в повести Художник она нарисовала уже иной образ автобиографической героини, сделав её устремленной к творческим завоеваниям и открытиям. Что не совсем, как мы покажем в дальнейшем, соответствовало действительности, ибо личностные особенности Кузнецовой отнюдь не ограничивались творческими интересами.

И на страницах ее дневника, который она ведет практически с первого дня пребывания рядом с Буниным, подспудно возникают иные интенции, которые идут вразрез с обозначенными выше свойствами. В реальной жизни у Кузнецовой явно возникало и аккумулировалось сопротивление, приведшее, в конце концов, к поступку, который можно квалифицировать как вызов: Кузнецова покидает Бунина, выбрав в качестве подруги жизни женщину - Марго Степун. Насчет лесбийских интенций ее природного естества в среде исследователей не сложилось определенного убеждения. Нам же представляется, что так в конце концов проявилось её растущее неприятие существующего положения вещей, желание вырваться из-под бунинской опеки. Все это отчетливо демонстрирует ее Грасский дневник, который, несмотря на тщательную правку перед публикацией, несмотря на отчетливое стремление автора убрать „лишние” подробности, увести в тень мотивы многих поступков, все же обнажает тайные переживания и рисует нарастание будущего конфликта. И одной из очень весомых причин расхождения Кузнецовой и Бунина (помимо разного жизненного целеполагания, различных устремлений) было, несомненно, возрастное несовпадение.

Бунин был старше Галины на тридцать лет. Он родился в 1870 году, Кузнецова — в 1900. Казалось бы, не такой большой срок — в истории культуры известны счастливые союзы с еще большей разницей в возрасте. Ведь и жена Бунина была моложе его на одиннадцать лет. Но в случае с Кузнецовой это возрастное несовпадение оказалось поистине роковым. И раньше всех этот возрастной контраст почувствовала Вера Николаевна Бунина, которая делает в своем дневнике, хотя, вероятно, и со ссылкой на мнение мужа, о чем-то смутно догадывающегося, уже в ноябре 1926 года запись следующего содержания: „Он понимает, что может увлечь, но это не настоящее. Отдельн(ый) кабинет, ужин, момент усталости, она смотрит, увидит морщину и подумает: стар"5.

${ }^{5}$ Ibidem. 
Как можно судить из приведенной цитаты, Бунин рассматривает и оценивает происходящее со стороны. Словно художник, он выхватывает эпизод из сюжетной цепи событий. Иначе он не умеет. Он не любовник, а творец, прежде всего, и это явственно ощущалось его молодой возлюбленной.

Но есть подозрение, что и Вера Николаевна, возможно, того не желая, тоже подливала масло в огонь разгоравшегося непонимания (думается, что она желала таким образом оградить Ивана Алексеевича от будущих разочарований). Об этом свидетельствует сделанная Галиной запись её слов в Грасском дневнике: „В.Н. [...] говорила, что [...] он [Зуров. - М.М.] внес в дом оживление, молодость и влияет на меня в этом смысле, а то я чересчур поддаюсь влиянию И.А., живу вредно для себя, не по летам"б [курсив мой. - М.М.]. Если смысл передан верно, то можно уловить намек на вредное влияние, оказываемое Иваном Алексеевичем на Кузнецову, которая лишалась радости, присущей молодости. Вера Николаевна верно угадала присущую Галине жажду развлечений, блеска и, внимательно приглядываясь к каждому нюансу её настроения, поддерживала в ней эти желания. Она заметно сопереживает тому, что „Галя киснет”. Она соболезнует ей по поводу отсутствия общения со сверстниками и постоянно фиксирует свое внимание (делясь этими наблюдениями с окружающими, по-видимому, тоже) на том, что юность девушки проходит в глуши, вдали от светских удовольствий, что у нее нет нарядов да и некуда их надеть.

Не приходится сомневаться, что добрейшая Вера Николаевна искренне сочувствует Кузнецовой, к которой относится едва ли не как к дочери, и хочет ей помочь, поэтому старается порадовать её обновами, при первой возможности покупает ей чулки, ботинки, замшевые перчатки, дарит шляпу. И в итоге с удовлетворением замечает: „[...] одели «как куколку», и «она стала, как с картинки», а посему «была счастлива»" очевидно культивирует в Галине тяготение к роскоши и беспечной жизни и даже возмущается предложением Ильи Фондаминского найти для неё в Париже какую-то работу, которая могла бы обеспечить её существование (несколько лет та живет за счет Буниных).

Прекрасно зная, что Бунину как ничто другое претит лень и безделье, она, тем не менее, именно к безделью подталкивает Кузнецову. „Галю превратить в бегающую по лекциям девицу, живущую нищенски, когда ей хочется именно «красоты жизни», «посильней роскоши»", возмущенно замечает она. Но именно этот факт заставляет ее провести четкую границу между „своим” (т.е. бунинским) поколением, которому безделье несвойственно, и молодыми, которые кажутся ей эгоистичными,

${ }^{6}$ Г. Кузнецова, Грасский дневник. Рассказы. Оливковый сад, Москва 1995, с. 127 (запись от 8 янв. 1930 г.).

${ }^{7}$ И.А. Бунин, „...Когда переписываются близкие люди”, с. 577.

8 Ibidem.

${ }^{9}$ Ibidem. 
сосредоточенными на себе, а потому душевно бедными. И этим своим наблюдением, вероятнее всего, делится с мужем.

Таким образом, проследив отношение Веры Николаевны к Кузнецовой, можно констатировать, что, скорее всего безотчетно, она всемерно подчеркивала „несовпадение” интересов и взглядов писателя и его молодой возлюбленной, провоцируя в поведении Галины те черты, которые были способны отдалить и отделить ее от Бунина. Действуя таким, казалось бы, парадоксальным образом - ведь обычно стареющая женщина, ревниво относясь к молодой сопернице, склонна игнорировать ее молодость, сглаживать возрастную разницу между ними, - Вера Николаевна, напротив, всемерно подчеркивала это различие, буквально выпячивая все сопутствующие негативные моменты, а именно: желание „жить для себя”, — вызывая у Бунина тем самым неприятие этих черт и комплекс старости. Можно сказать, что Вера Николаевна многое сделала для того, чтобы Галина оказалась в объятиях Магды Степун, потому что именно та могла обеспечить если не роскошную, то веселую и беззаботную жизнь для своей подруги, что, возможно, и привлекло к ней Кузнецову. Это не значит, что она подталкивала ее именно к женщине: в какой-то момент была надежда на Рощина, который сумеет как ровесник отвлечь молодую женщину от грустных мыслей. Но у него оказался тяжелый характер. И именно Магда оказалась подходящей спутницей для Галины.

Особенно это станет ясно во второй приезд „барышень” в Грасс, когда они начнут все больше времени проводить у друзей в Каннах. Неосознаваемая подоплека действий Веры Николаевны выплывет наружу в её письме к мужу, когда она разрыв Галины с грасской жизнью объяснит тем, что он „перекормил” Галю собой, и ей стало „неинтересно“"10. Иными словами, она подчеркнет их чуждость друг другу... К теме возраста Вера Николаевна вернется еще раз, уже в 1936 г., когда после своей встречи с Галиной в Париже укажет в письме к Бунину, что та стала „взрослее”, словно бы напомнив ему, какой молодой и несмышленой она была раныше. Однако и сама Галина отныне не будет скрывать от Бунина сущности своего характера. Она честно напишет ему, что больше всего ей „хочется только лежать на траве и ни о чем не думать". И пожелает она своему старшему другу того, чего ему, на её взгляд, не хватает: чтобы „перемена обстановки, солнце” способствовали исчезновению в нем чего-то „очень и очень горького"11. Так она обозначит горечь старости в противовес безмятежности собственной молодости.

Надо признать, что и ранее на страницы дневника проникали ее заметки о признаках в Бунине старости и утомления. Ей кажется, что раньше такого не было, а сейчас, летом 1928 года, т.е. спустя всего год после прибытия в Грасс, ей это бросается в глаза:

10 Ibidem, c. 583-584.

11 Ibidem, c. 590 (приписка к письму В.Н. от июля 1938 г.). 
Вообще И.А. не тот, что был раньше. Перемена эта трудно уловима, но я знаю, что она в отсутствии той молодой веселой отваги, которая была в нем год-два назад и так пленяла [обратим внимание на глагол, означающий, что теперь пленяться, по-видимому, нечем. - М.М.]. Он внутренне притих ${ }^{12}$.

И далее несколько раз встречается упоминание того, как эта перемена — „тяжкой тоской” - отражается на ее самочувствии. Постепенно эта тоска разрастается до ощущения „голости” всей жизни, грасский дом кажется неуютным: ледяная вода в умывальнике, холодные комнаты, а главное - длинные-длинные вечера, которые нечем заполнить. Последнее выглядит особенно поразительным. Скучно рядом с Буниным! Вечерами не ведутся беседы, что было еще совсем недавно... Чувство „жалобной грусти и пустоты" 13 усиливается после блеска пребывания в Стокгольме во время вручения Нобелевской премии. Кузнецова начинает все больше осознавать, что невозможно бесконечно пребывать в „полудетях”, как в шутку называли молодое поколение грасских обитателей.

Обобщит свои ощущения того времени она позже (приблизительно в 50-е годы) в эссе-очерке Друзья, в центр которого поставлен Фондаминский, наиболее близкий ей тогда человек. Его роль по введению ее в „слишком "взрослую»" для нее жизнь Бельведерской виллы здесь всемерно подчеркивается. Значит, спустя почти 20 лет она твердо помнит, что была „наполовину младше всех живущих"14 там. И это уже выглядит как приговор.

Бунин в очерке „проходит” фоном. Но тем более показательны те, опять-таки, итоговые формулировки, которые возникают в ее творческом сознании. Портрет писателя воссоздан уже с опорой на мифологию, которая сложилась в бунинской иконографии и мемуаристике: „сухощавый, небольшой, стройный”, одетый во все белое, „горделиво закинутая, выбритая наголо по-летнему голова и профиль римского патриция" ${ }^{\prime 2}$. В соответствии с возникающим каноном изображения в облике Бунина педалируется именно юношеское начало. В очерке Друзья Бунин в противовес грасскому дряхлому дому молод; его „стремительная рука” по утрам бодро распахивает ставни, он „стремительно сбегает по лестнице своей легкой, почти юношеской походкой" 16 . Таким будет нарисован и Шатилов в ее неоконченной повести Художник, над которой она работала приблизительно в это же время (в его образе „соединились” черты Бунина и ее поклонника художника Савелия Абрамовича Сорина). Но и в образе Шатилова постепенно будет проступать что-то мертвенное, что будет проявляться в доминировании желто-коричневых оттенков сопровождающей его колористической гаммы. Так и в Друзьях подлинное отношение Кузнецовой к Бунину будет проступать

\footnotetext{
12 Г. Кузнецова, Грасский дневник..., с. 73.

13 Ibidem, c. 295.

14 Г. Кузнецова, Друзья, [в:] Мы. Женская проза.., с. 286.

15 Ibidem, c. 283.

${ }^{16}$ Ibidem, c. 284.
} 
в подтексте описания мертвенно-ритуального распорядка в доме, определяемого диктаторской миссией его хозяина. В уютных креслах на террасе никто по утрам не нежится, ибо надо ,утром рано встать бодрым, выспавшимся, полным творческих сил для работы”. А для того чтобы сохранить этот настрой и бодрость, надо „рано ложиться”17. Поэтому „соловьиное пение, роса в высокой траве, звездочки мелких белых цветов, раскрывавшихся по вечерам на верхних пустых террасах”, „опьяняющее благоухание цветов” одаряет обитателей дома только „на миг”

Остальное же, кажущееся Кузнецовой бесконечно длящимся, время подчинено „одному и тому же образцу”, той иерархии ценностей, что задана Буниным и вершиной которой является, конечно же, писание, творчество, рабочая дисциплина.

Думается, что неслучайно ритуализированность и монотонность действий воспринимается автором эссе Друзья в параметрах той же выхолощенной обрядовости, которая воспроизведена Буниным в Господине из Сан-Франциско (эталонном для Кузнецовой произведении писателя). Это подтверждается почти идентичностью фраз, дающих представление об отработанной жизненной схеме. На пароходе Атлантида, где разворачивается действие бунинского рассказа, жизнь

протекала весьма размеренно: вставали рано [...], садились в ванны, делали гимнастику, возбуждая аппетит и хорошее самочувствие [...] полагалось бодро гулять по палубам [...] подкрепляться бутербродами [...],

ожидая трубного сигнала, возвещающего о том, что „составляло главнейшую цель всего этого существования"19 — роскошного ужина и бала. То же происходило и в Неаполе, куда прибыл господин из Сан-Франциско и где жизнь „тотчас же потекла по заведенному порядку" 20 . По замыслу Бунина, такая монотонность и вычисленность должны символизировать человеческую пустоту американца, подготавливающего себя к приему очередной порции наслаждения, которое для него и является „венцом” такой жизни. Но для Кузнецовой это оказывается тем же однообразием, что сопутствует приуготовлению к писательскому поприщу. Ведь и для обитателей виллы Бельведер писательство тоже является „венцом” и конечной целью существования („Все здесь работали”21), а для нее оно постепенно начинало идентифицироваться с самоустранением от жизни, неспособностью принять и ощутить её полноту и великолепие. Поэтому можно предположить,

17 Ibidem, c. 285 .

18 Ibidem.

19 И. Бунин, Господин из Сан-Францฺиско, [в:] idem, Собрание сочинений в девяти томax, под общей ред. А.С. Мясникова, Б.С. Рюрикова, А.Т. Твардовского, т. 4, Москва 1966, c. 309-310.

20 Ibidem, c. 313.

${ }^{21}$ Г. Кузнецова, Друзья..., с. 285. 
что, подталкивая Кузнецову к писательскому труду, Бунин добился совершенно противоположного результата, обрисовав для нее ту формулу аскетического существования, которую она, в силу свой натуры, категорически не хотела принять. Возможно, именно поэтому, обладая несомненным дарованием, она раз и навсегда отвергла для себя возможность стать писателем высокого ранга, что требовало погружения в творческий процесс и самоограничения.

В свое время жесткий приговор женской молодости вынес Блок. При подготовительной работе над пьесой Роза и крест он сделал следующую запись, касающуюся его героини: „как во всех молодых, в ней сладостно борются [...] два стремления: одно - пошлое, житейское, сладострастное и другое, открывающее «высокие и женственные возможности»"22. Бунин надеялся развить в Галине эти высокие возможности. Но она предпочла стать не крупной писательницей, а просто счастливой и любящей женщиной.

\section{Библиография}

Блок А., „Роза и Крест” [планы и заметки], [в:] idem, Собрание сочинений в восьми томах, т. 4, под общей ред. В.Н. Орлова, А.А. Суркова, К.И. Чуковского, Москва-Ленинград 1961.

Бунин И., Господин из Сан-Франциско, [в:] idem, Собрание сочинений в девяти томах, т. 4, под общей ред. А.С. Мясникова, Б.С. Рюрикова, А.Т. Твардовского, Москва 1966.

Бунин И.А., „,..Когда переписываются близкие люди”. Письма И.А. Бунина, В.Н. Буниной, Л.Ф. Зурова к Г.Н. Кузнецовой и М.А. Степун. 1934-1961, „Новые материалы”, вып. III, сост., подгот. текста, науч. аппарат Е.Р. Пономарева и Р. Дэвиса, Москва 2014.

Кузнецова Г., Грасский дневник. Рассказы. Оливковый сад, Москва 1995.

Кузнецова Г., Друзья, [в:] Мы. Женская проза русской эмиграции, сост., вступ. статья и комментарии О.Р. Демидовой, Санкт-Петербург 2003.

Кузнецова Г., Художник, [в:] Мы. Женская проза русской эмиграции, сост., вступ. статья и комментарии О.Р. Демидовой, Санкт-Петербург 2003.

\section{Creative relationship between I.A. Bunin and Galina Kuznetsova as a youth and aged conflict}

\section{Summary}

In general the literary criticism considers a creative relations between I. A. Bunin and G. N. Kuznetsova as a Student-Teacher relationship, and not as regards of two equal artists. But this aspect was elected by the author, because there is still no answer to the question why Kuznetsova's

22 А. Блок, ,Роза и Крест” [планы и заметки], [в:] idem, Собрание сочинений в восьми mомах, под общей ред. В.Н. Орлова, А.А. Суркова, К.И. Чуковского, т. 4, Москва-Ленинград 1961, c. 458. 
bright poet and novelist debut, which was implemented with the assistance of Bunin, has not received appropriate continuation (in fact she has remained the author of Grassky Diary only). There is an attempt, using the support of creative psychology and personal singularity of the art union members, to understand the causes of the student internal resistance to the Master exposure, and her rebellion that led to their disruption. It was moved a "subtext" of the diary out, where a discrepancy is detected in an "objective" proclaimed content that was aimed to the Bunin enlargement. It concludes that "the Bunin image" is doubled on the pages, and a source of misunderstanding is in conflict between a youth and aged which Kuznetsova is aware acutely, who were the first to realize Vera Bunina.

Keywords: creativity, youth, old age, "Grasse diary", Vera Bunina, modeling character, the author's self-representation

\section{Relacje twórcze Iwana Bunina i Galiny Kuzniecowej — konflikt młodości i starości}

\section{Streszczenie}

W historii literatury relacje twórcze Iwana Bunina i Galiny Kuzniecowej rozpatrywano zazwyczaj jako związek nauczyciela i uczennicy, a nie jako relacje dwóch równoprawnych osobowości twórczych. Tymczasem ten właśnie aspekt interesował autorkę artykułu, ponieważ do tej pory nie ma odpowiedzi na pytanie: dlaczego błyskotliwy debiut poetycki i prozatorski Kuzniecowej, zrealizowany przy współudziale Bunina, nie doczekał się kontynuacji? (Kuzniecowa w istocie pozostała wyłącznie autorką Dziennika z Grasse). W artykule podjęto próbę — w oparciu o psychologię twórczości oraz rozpoznanie osobowości uczestników owego związku — wyjaśnienia przyczyn wewnętrznego oporu uczennicy wobec wpływu Mistrza i jej buntu, które doprowadziły do rozstania. Ujawniony został „podtekst” Dziennika, który wskazuje na niezgodność z „obiektywną”, pierwszoplanową treścią, ukierunkowaną na uwznioślenie Bunina. Konkludując: „obraz Bunina" na kartach Dziennika rozdwaja się, a źródłem niezrozumienia jest konflikt młodości i starości, intensywnie odczuwany przez Kuzniecową, który najwcześniej wyczuła Wiera Bunina.

Słowa kluczowe: twórczość, młodość, starość, Dziennik z Grasse, Wiera Nikołajewna Bunina, modelowanie bohatera, autoreprezentacja autora 